\title{
THE GENETICAL SOCIETY OF GREAT BRITAIN
}

\author{
ABSTRACTS of Papers presented at the HUNDRED AND SEVENTY-EIGHTH \\ MEETING of the Society held on 8th, 9th and 10th JULY 1975 at the \\ JOHN INNES INSTITUTE, NORWICH.
}

\section{CONTROL MUTANTS OF ARGININE METABOLISM IN BACILLUS SUBTILIS}

\author{
S. BAUMBERG and C. R. HARWOOD
}

Department of Genetics, University of Leeds and Biological Laboratory, University of Kent

In Bacillus subtilis 168, at least three enzymes of arginine biosynthesis are repressed, and the enzymes arginase and ornithine transaminase (OTAse) are induced, by arginine. The strain is inhibited by the analogue arginine hydroxamate; Kisumi et al. (Appl. Microbiol., 22, 987, I97I) showed that some resistant mutants excrete arginine. We obtain spontaneous arginine hydroxamate-resistant mutants at frequencies of the order of $3 \times 10^{-5}$. Although some isolates are unaltered in the activity of enzymes of the arginine pathways, many show reduced levels of arginase and OTAse. We have so far identified seven such phenotypic classes. In all of these, arginase and OTAse are both affected but to different extents, and we therefore tentatively propose that they are control mutants. In at least three mutant classes, one or more of the biosynthetic enzymes is synthesised at a high partially or completely constitutive level also. We conclude that the control systems for repression of the biosynthetic enzymes and induction of the catabolic enzymes share at least one component. It is noteworthy that these pathways in the yeast Saccharomyces cerevisiae, which are biochemically similar to those in B. subtilis, show (at least formally) the same linked control (Wiame, Current Topics in Cellular Regulation, 4, 1, 1971). Representatives of six classes have been roughly mapped by transduction with phage PBSI. They are $c .15$ per cent co-transducible with cys $A$.

\section{THE tamA LOCUS IN ASPERGILLUS NIDULANS}

\author{
J. A. PATEMAN and J. R. KINGHORN \\ Department of Genetics, University of Glasgow, Glasgow
}

Mutants designated $\operatorname{tam} A^{r} I I g$ etc., formerly $a m r B$ (Kinghorn and Pateman, Heredity, 31, $427,1973)$ have been described which are resistant to the toxic analogues thiourea, aspartic hydroxamate, methylammonium and chlorate with L-alanine as the sole nitgoren source. The resistance of $\operatorname{tam} A^{r}$ mutants is correlated with partially repressed levels of some enzyme and transport systems regulated by ammonium. Furthermore, tam $A^{r}$ mutants have low NADP-glutamate dehydrogenase activity and also efflux ammonium under certain conditions. This mutant isolation method also generated partially repressed mutants at the are $A$ locus (Arst and Cove, Molec. gen. Genet., 126, $111-141$, 1974).

A fully repressed allele of $\operatorname{tam} A$ has been made $\left(\operatorname{tam} A^{r} 5^{\circ}\right)$. It is unable to utilise a number of inorganic and organic nitrogen sources and only grows normally on ammonium.

A revertant of $\operatorname{tam} A^{r}$ was selected on the basis of sensitivity to the toxic analogues in the presence of ammonium. This depressed allele, designated $\operatorname{tam} A^{d_{I}}$ is insensitive to ammonium control of a number of ammonium repressible systems.

The dominance of these alleles will be discussed as well as the phenotypes of double mutants containing $\operatorname{tam} A$ alleles and other regulatory mutants affecting ammonium control. The properties of the various $\operatorname{tam} A$ alleles establish that $\operatorname{tam} A$ is a regulatory gene involved in the control of nitrogen and/or carbon metabolism in $A$. nidulans. 


\title{
THE DETERMINANTS OF GENE CONVERSION PROPERTIES IN ASCOBOLUS IMMERSUS
}

\author{
M. R. T. WICKRAMARATNE and B. C. LAMB \\ Department of Botany, Imperial College, London
}

\begin{abstract}
One method of assessing hybrid-DNA models of recombination and gene conversion is to examine how far conversion properties at particular heterozygous sites are determined by the nature of those sites and their postulated mispairs in hybrid-DNA. Other possible determinants include the nature of neighbouring sites, and regions of the genome which have general effects on recombination and conversion, or specific, localized effects on other regions.

The Pasadena strains of Ascobolus immersus (Emerson and Yu-Sun, Genetics, 55, 39-47, 1967) were used here in such an investigation, with one- and two-point crosses of white ascospore mutants, $w-I O$ and $w-78$. Conversion properties of each site in different genetic backgrounds were determined from crosses to genetically different isolates and from crosses involving alleles before and after they had undergone conversion. The effects of temperature on conversion in different crosses were also investigated. It was found that conversion parameters at a site were not solely determined by the nature of that site; nearby genetic factors were much more important than ones elsewhere in the genome.
\end{abstract}

\section{SIZE AND BASE COMPOSITION OF RNA PRIMERS OF PLASMID DNA SYNTHESIS}

\author{
P. H. WILLIAMS, R. W. LEAVITT, H. W. BOYER and D. R. HELINSKI \\ Department of Biology, University of California, San Diego, La Jolla, and \\ Department of Microbiology, University of California Medical Center, San Francisco
}

Colicinogenic plasmid El (Col El) DNA replicates unidirectionally from a unique origin. Continuous synthesis of the " light" daughter DNA strand and discontinuous synthesis of the " heavy" daughter DNA strand both require priming events involving short RNA molecules. In the presence of chloramphenical (CM), Col El DNA replicates normally except for adventitious covalent integration of primer ribonucleotides in supercoiled daughter DNA molecules (CM-Col El DNA).

Preparations of CM-Col El DNA were separated into samples with a gap resulting from hydrolysis of ribonucleotides in only one of the complementary daughter DNA strands. These samples were substrates for in vitro repair resynthesis reactions with Rous sarcoma virus DNA polymerase and $\alpha-{ }^{32} \mathrm{P}$-labelled deoxyribonucleoside- $5^{\prime}$-triphosphates. Incorporation of each labelled nucleotide in the presence of three unlabelled nucleotides was measured. Also, incorporation of all four labelled nucleotides was followed by exhaustive nuclease digestion and electrophoretic analysis of products.

By these two approaches, the RNA segment in the "light" DNA strand (the postulated initiation primer) was found to comprise 38 ribonucleotides of average base composition 17G, 5A, 8C, 8U. The RNA in the " heavy" DNA strand (a primer for discontinuous synthesis) consists of 15 ribonucleotides with an average composition of $5 \mathrm{G}, 2 \mathrm{~A}, 4 \mathrm{C}, 4 \mathrm{U}$.

\section{VARIATION IN CHROMOSOME ASSOCIATION PATTERN IN AUTOPOLYPLOIDS}

\author{
M. GUL HOSSAIN \\ Department of Botany, University of St. Andrews \\ and \\ K. MOORE \\ Department of Plant Science, University of Newcastle upon Tyne
}

There is controversy about the effect of chromosome pairing configurations of an autotetraploid on the formation of balanced gametes which ultimately determine the level of seedset. Some workers suggested that multivalent configurations are responsible for irregular 
chromosome separation at meiosis and the consequent low fertility in autopolyploids (cf. Müntzing, Hereditas, 37, 17, 1951). Another set of experiments demonstrated that higher quadrivalent frequency is correlated with higher fertility (cf. Hazarika and Rees, Heredity, 22, $317,1967)$. Other workers reported that quadrivalents are of minor importance in meiotic regularity and fertility (cf. Myers, Bot. Rev., 13, 518, 1957; McCollum, Chromosoma, Bd. 9, 571, 1958) while some others claimed that bivalent frequency is associated with fertility of autotetraploids (cf. Aastveit, Hereditas, 60, 294, 1968).

It is probable that differences between experimental materials for chiasma frequency and/ or their distribution pattern may largely account for this wide range of discrepancy in the results obtained. The results of meiotic investigations in an advanced population of tetraploid rye will be discussed in relation to the results reported for inbred materials (Hazarika and Rees, l.c.). It will be demonstrated that chiasma distribution pattern in the present randommating population is fundamentally different from that of inbred lines.

\title{
FLAVONOID GLYCOSYLATION GENES IN EUROPEAN POPULATIONS OF SILENE DIOICA AND S. ALBA
}

\author{
G. VAN NIGTEVECHT and J. VAN BREDERODE \\ Genetical Institute, University of Utrecht, Utrecht, The Netherlands
}

In the petals of $S$. dioica gene $M$ controls the glycosylation of the 5-OH group and gene $\mathcal{N}$ the rhamnosylation of glucose of cyanidin 3-0-glucoside. S. alba does not contain anthocyanin in the petals and is $m / m, n / n$. S. dioica and $S$. alba petals also contain glycosides of isovitexin. The following isovitexin-glycosylation genes have been demonstrated: $g^{G}$ and $g^{X}$ control the binding of glucose and xylose respectively to the 7-OH group; $g l^{A}, g l^{R}$ and $F g$ control the binding of arabinose, rhamnose and glucose respectively to the 6-C-C- bound glucose of isovitexin. The genes $g^{G}, g^{X}$ and $g$ are alleles, the same holds for the genes $g l^{A}, g^{K}$ and $g l$.

In $S$. dioica the genes $g^{X}, g l^{A}$ and $F g$ are found, whereas in $S$. alba $g^{G}$ and $g l^{R}$ are present. These genes display a remarkable geographical distribution in $S$. alba. West of the $0^{\circ} \mathrm{C}$ January isotherm $g l^{R}$ is missing or rare, where the frequency of $g^{G}$ is 1 . Eastwards the frequency of $g^{G}$ is often less than 1 and is very low in Hungarian populations. The role of selection and change in this distribution is being investigated.

The impact of these genes on flower morphology, pollination and other pleiotropic effects also have been investigated.

The possible correlation between the spreading of agriculture and of $S$. alba in Europe is considered and gene exchange with other species is studied. Notable is our finding of the crossability of $S$. alba with Melandrium quadrilobum from Siberia which probably contains the same glycosylation gene as predominates in $S$. alba in eastern Europe.

\section{GENETIC CONTROL AND BIOSYNTHESIS OF ANTHOCYANIDIN-GLYCOSIDES IN THE PETALS OF SILENE DIOICA}

\section{J. VAN BREDERODE, G. VAN NIGTEVECHT and J. KAMSTEEG Genetical Institute, University of Utrecht, Utrecht, The Netherlands}

Apart from several genes which control the amount of anthocyanidin-glycosides present, the formation of anthocyanidin-glycosides in $S$. dioica is governed by the genes $C, A, P, M$ and $\mathcal{N}$.

In the absence of a dominant allele of gene $C$ no anthocyanidin-glycosides are present in the whole plant. Gene $A$ governs the formation of anthocyanin in the petals. Gene $P$ controls the introduction of a hydroxylgroup at the 3'-position of the anthocyanidin-skeleton. Gene $M$ controls the glucosylation of both cyanidin and pelargonidin 3-0-glucosides to their respective 3,5 diglucosides whereas gene $\mathcal{N}$ governs the binding of rhamnose to the glucose position of both the 3-0-glucosides and the 3,5 diglucosides of pelargonidin and cyanidin.

Although no gene responsible for the anthocyanidin 3-0-glucosylation could be detecteduntil now no plants with solely an anthocyanidin aglycone have been found-the enzymatic formation of cyanidin 3-0-glucoside from UDP-glucose and cyanidin could be demonstrated. 
The enzyme had a maximal activity at $p \mathrm{H} 7 \cdot 5$, an apparent $\mathrm{K}_{m}$ value for UDP-glucose of $0.7 \mathrm{mM}$ and was not influenced by the divalent cations $\mathrm{Mg}^{2+}$ and $\mathbf{M n}^{2+}$. For maximal activity the presence of an emulgator was necessary.

An enzyme catalysing the transfer of glucose from UDP-glucose to the 5-OH group of cyanidin 3-0-rhamnosy-glucoside was also identified. This activity however, was dependent upon the presence of a dominant allele of gene $M$.

\title{
POLYPLOIDY, GENETIC CONTROL OF CHROMOSOME PAIRING AND EVOLUTION IN THE FESTUCA-LOLIUM COMPLEX
}

\author{
PREM P. JAUHAR \\ Welsh Plant Breeding Station, Aberystwyth
}

\begin{abstract}
Although organic evolution and speciation are slow processes, allopolyploidy provides a basis for rapid or even cataclysmic evolution. It is this fact which led Haldane (1958) to change Blake's (1792) statement to read: "To create a little flower is the labour of ages, except by allopolyploidy" (the italicised portion added by Haldane); a little flower in this quotation means a new species. Hybridisation between related species followed by chromosome doubling has no doubt given rise to our most important grain, fodder and fibre crops. It is felt strongly, however, that the superimposition of a precise genetic control on chromosome pairing or disjunction is vital for conferring meiotic, and hence reproductive, stability in sexually reproducing polyploids. I further feel that polyploidy and sexuality cannot coexist in nature without such a regulatory mechanism. Polyploids found in nature without a genetic control are probably apomictic and, hence, blind alleys from the evolutionary standpoint.

The role of polyploidy in conjunction with genetic regulation of chromosome pairing will be discussed with particular reference to evolution in the Festuca-Lolium complex. Justification will also be presented for the further modification of the above quotation to read as: "To create a little flower is the labour of ages except by allopolyploidy coupled with genetic control of chromosome pairing ".
\end{abstract}

\section{LEAF DEVELOPMENT IN CONTRASTING POPULATIONS OF DACTYLIS}

\author{
C. F. EAGLES \\ Welsh Plant Breeding Station, Aberystwyth
}

Populations of Dactylis glomerata from contrasting climatic regions show different patterns of leaf expansion in a range of environments. These differences are most marked at low temperatures under short day conditions with a Norwegian population showing reduced leaf expansion associated with diversion of assimilates to storage, while a Portuguese population continued active leaf expansion. These contrasting strategies of assimilate utilisation were altered by hormone applications, and appear to be related to endogenous hormone levels.

Differences in leaf size between these populations, daylengths and hormone treatments were associated with differences in cell size. Comparisons of physiological characters expressed on a cell basis are presented.

Leaf expansion characteristics of the progeny of a cross between a northern population and the colchiploid of the Portuguese population indicate the possibility of developing potential varieties with favourable " out of season" growth as well as summer growth.

\section{VARIATION FOR COMPONENTS CONTRIBUTING TO FLOWERING TIME IN ANTIRRHINUM MAJUS}

\section{L. HEDLEY}

John Innes Institute, Norwich

Physiological studies of the control of flowering time have been initiated using contrasting varieties of Antirrhinum majus. The initial aim of this work was to identify the main environmental factors affecting flowering time and to look for varietal differences for response to particular environments. 
Variation has been observed for response to photoperiod at low light intensity and for sensitivity to photoperiod at high light intensity. Light-breaks have been used in an attempt to separate the effects of increased light energy from photoperiodic responses.

The physiological observations will be used to provide criteria for the selection of new varieties which are more responsive to photoperiod and which grow more rapidly in poor environmental conditions.

\title{
SEED DEVELOPMENT IN PISUM SATIVUM
}

\author{
D. R. DAVIES \\ John Innes Institute, Norwich
}

The variation in cell population, average cell size, growth rate and period of development of the cotyledons has been examined in a number of varieties of Pisum sativum having a range of seed sizes. A further series of studies have involved determining DNA, ribosomal RNA and ribosomal DNA amounts in these tissues. The relationship of these parameters to seed development will be considered.

Reciprocal crosses of contrasting varieties can prove particularly useful in determining the nature of the control of these parameters; in such crosses identical genotypes can have markedly different phenotypes and similar phenotypes can have dissimilar genotypes. The respective roles of the seed's own genotype and of the maternal parent can be thus discriminated.

\section{THE OPERATION OF GIBBERELLIN INSENSITIVITY GENES IN DWARF WHEATS}

\author{
M. GALE \\ Plant Breeding Institute, Cambridge
}

A number of dwarf mutants in Triticum aestivum have been found to have an insensitive reaction to the hormone gibberellic acid (GA). Extracts from these dwarfs show high levels of endogenous GA indicating that turnover of the hormone is restricted.

Three genes of differing potency, $G_{a i_{1}, 2}$ and ${ }_{3}$, have been identified. $G_{a i}$ and $G a i_{3}$ have been located on homoeologous chromosomes indicating a functional identity between quantitatively dissimilar genes. Observations of the extent of GA-insensitivity during growth indicates a mode of action based on changing threshold levels of gene products. These thresholds are also tissue dependent and only $\mathrm{Gai}_{3}$ operates in the aleurone to restrict the GA-induced enzyme response. In this tissue triploid inheritance is observed.

\section{PRECURSORS AND GENETIC CONTROL OF ANTHOCYANIN BIOSYNTHESIS}

\author{
B. J. HARRISON and R. G. STICKLAND \\ John Innes Institute, Norwich
}

Anthocyanin synthesis has been induced in white-flowered genotypes of many flowers after feeding of flavonoid precursors or of homogenates of other white flowers. The anthocyanin formed depended on the precursor used and the hypostatic genes of the flower. Thus in Antirrhinum majus, dihydrokaempferol gave pelargonidin $(\mathrm{Pg})$ or cyanidin ( $\mathrm{Cy}$ ), dihydroquercetin gave $\mathrm{Cy}$, and dyhidromyricetin $(\mathrm{Dhm})$ gave delphinidin $(\mathrm{Dp})$, which is not otherwise found in A. majus. A homogenate of pink A. majus flowers (with the Pg removed) produced $\mathrm{Pg}$ or $\mathrm{Cy}$ (according to the recipient's genotype) when fed to albino A. majus flowers, and malvidin when fed to Streptocarpus (Maassen's White) flowers. Similarly, an extract of Rhododendron lanigerum leaves (containing $\mathrm{Dhm}$ ) induced $\mathrm{Dp}$ synthesis in white $A$. majus flowers. Results confirm the anthocyanin biosynthetic pathway and the technique enabled hypostatic genes to be identified quickly and permitted screening of plant populations for genetic variations in pigment production. 


\title{
GENETICAL STUDIES ON THE DEVELOPMENT OF PHYSCOMITRELLA PATENS
}

\author{
D. J. COVE and N. W. ASHTON \\ Department of Genetics, University of Cambridge
}

The moss, Physcomitrella patens is proving to be a very suitable system for the study of the genetic programming of development. Mosses show a well ordered development, and extensive studies have been carried out particularly in Germany, into the physiological basis of the developmental changes. Genetics is now being used to attempt to elucidate their molecular basis. In particular the process of bud formation is being investigated. Previous studies have shown that this is a cytokinin induced process, particular target cells concentrating the hormone, and responding by growth to form a bud. We have isolated mutants blocked in this stage and using these we are attempting to characterise the genetic basis of this response. We have also isolated mutants which produce many more buds than the wildtype.

Most developmental mutants are sterile, and protoplast fusion using biochemical mutants we have obtained, is being developed as an alternative to the normal sexual cycle.

\section{GENETICS OF PSEUDOMONAS}

\author{
P. H. CLARKE \\ Department of Biochemistry, University College Lonton
}

Genetic exchange in $P$ seudomonas aeruginosa and $P$. putida can be mediated by both conjugation and transduction. The sex factor FP2 promotes chromosome transfer in $P$. aeruginosa strains PAO and PAT. Although at one time it was suggested that the genetic material of this species might form two separate linkage groups, recent physicochemical data (Pemberton 7. Bact., 119, 749, 1974), and more detailed genetic analyses indicate that the bulk of the genetic material is organised in a single chromosome. Genetic circularity of the Pseudomonas chromosome has yet to be established. The chromosome has been partially mapped by interrupted mating and transduction has been used to map within shorter gene regions. Several temperate bacteriophages are available for transductional analysis (Holloway, Krishnapillai and Stanisich, Ann. Rev. Genet., 5, 425, 1971 ; Holloway; Stanisich and Richmond, in Genetics and Biochemistry of Pseudomonas. Eds. Clarke and Richmond, John Wiley, 1975).

RP plasmids, carrying multiple drug resistance, are freely transmissible between $P$ seudomonas species and can also be transferred to Escherichia coli and to other bacterial genera. Some RP plasmids can promote chromosomal transfer in Pseudomonas species.

$P$. putida strains may harbour plasmids carrying genes for the first few enzymes of a catabolic pathway including those for the utilisation of camphor (CAM), octane (OCT), naphthalene (NAH) and toluate (TOL). Some of the plasmids can be readily transferred to other $P$. putida and $P$. aeruginosa strains and may also be capable of promoting chromosome transfer. Transduction is also feasible with $P$. putida strains.

Recent data on chromosome mapping, the arrangement of genes on the chromosome, the properties of plasmids and the possible role of the catabolic plasmids in the evolution of metabolic diversity in this group of bacteria will be discussed.

\section{GENETIC ASPECTS OF SPORULATION IN BACILLUS SUBTILIS}

\section{P. J. PIGGOT \\ National Institute for Medical Research, Mill Hill, London NW7 IAA}

Some 200 distinct genetic loci are now known for Bacillus subtilis, and these lie on a single circular linkage map. More than 30 of the loci are specific to spore formation. They have been identified by mutations that block sporulation, but do not affect vegetative growth. Assuming that the mutations lie in genes which are inactive in vegetative growth and only switched on during spore formation, then there are at least 30 switch-on points on the genome, as the loci are well separated from each other. 
Asporogenous mutations are highly pleiotropic, causing the loss of a number of sporulation events. This has meant that, in general, the primary lesion is not known. It shows that sporulation proceeds by a highly dependent sequence of events, in which loss of any one prevents expression of later events. Studies of double mutants have indicated that the sequence is not a single linear sequence. Because of the pleiotropy, secondary mutations that lead to derepression of late sporulation events (such as phosphate-insensitive alkaline phosphatase formation) can be isolated from asporogenous strains. By combining these secondary control mutations with different asporogenous mutations it should be possible to work out the sequence of expression of the different loci.

\title{
GENETIC ASPECTS OF METABOLIC CONTROL IN PSEUDOMONAS AND BACILLUS
}

\author{
S. BAUMBERG \\ Genetics Department, University of Leeds, Leeds LS2 9JT
}

There are two aspects of the regulation of enzyme synthesis: the phenotypic pattern of control, i.e. response of enzyme synthesis to changes in medium and other environmental variables in wild-type and mutants; and the underlying genetic mechanisms responsible. In bacteria other than $E$. coli and its relatives, the detailed patterns have been thoroughly studied for a few systems, but even here knowledge of basic mechanisms is meagre.

Catabolic systems in the pseudomonads show induction and catabolite repression; the latter, however, is elicited by intermediary metabolites such as succinate rather than by glucose and related compounds as in the enterobacteria. Mutants can often be selected showing constitutive rather than inducible enzyme synthesis. A characteristic of the long, converging pathways of degradation of unusual carbon sources (e.g. mandelate) in this group is sequential induction, wherein blocks of enzymes are switched on in sequence, the product of one block causing induction of the next.

Biosynthetic pathways, such as those for tryptophan and arginine, in the pseudomonads may show a mixture of repressible, constitutive and inducible enzymes.

Control mutants have been described in the tryptophan and isoleucine-valine pathways.

In Bacillus subtilis the best studied catabolic system is that for sucrose. Here again the enzymes are inducible, and mutations at several loci lead to constitutivity or non-synthesis. Biosynthethic pathways usually show repressible enzyme production: constitutive mutants are known, e.g. for the tryptophan pathway.

\section{THE GENETICS OF RHIZOBIUM AND FREE-LIVING NITROGEN-FIXING BACTERIA}

\author{
J. E. BERINGER \\ John Innes Institute, Colney Lone, Norwich NR4 7UH
}

The reduction of atmospheric nitrogen to ammonia in biological systems is carried out by the enzyme nitrogenase, which consists of two oxygen-sensitive metalloproteins. The genes required for the synthesis of nitrogenase are widely distributed among prokaryotes, but nitrogen-fixing eukaryotes have not been observed. Despite the oxygen-sensitivity of nitrogenase, free-living aerobic and even photosynthetic nitrogen-fixing bacteria are known, as well as anaerobes. For certain species, such as Rhizobium, the expression of nitrogenase is apparently dependent upon a close intracellular association with a particular species of eukaryotic host plant.

Most of the genetic research into nitrogen fixation has been on two relatively easily handled free-living bacteria; the facultative anaerobe Klebsiella pneumoniae, which fixes nitrogen anaerobically, and the strict aerobe Azotobacter. Klebsiella pneumoniae has been chosen in particular because it is closely related to Escherichia coli, can be manipulated in a similar manner, and is susceptible to the generalised transducing phage P1 (S. L. Streicher, E. G. Gurney and R. C. Valentine, Proc. Nat. Acad. Sci. U.S.A., 68, 1174, 1971). The genetics of Azotobacter and Klebsiella will be reviewed. 
Symbiotic nitrogen-fixing associations, such as that between Rhizobium and some leguminous plants, are more difficult to study genetically as the expression of nitrogenase depends upon a successful interaction between the plant and bacterium. To facilitate studies of this symbiosis, Rhizobium genetics has been studied by a number of workers and reports of gene transfer have appeared in the literature. These will be reviewed.

Work in this laboratory on the production and study of symbiotically defective mutants of Rhizobium leguminosarum, together with studies of $\mathrm{R}$-factor mediated conjugation experiments in nodulating strains of $R$. leguminosarum has led to an unambiguous demonstration of genetic recombination in $R$. leguminosarum.

\title{
STREPTOMYCES GENETICS, ANTIBIOTIC SYNTHESIS AND RESISTANCE
}

\author{
D. A. HOPWOOD, M. J. BIBB, R. KIRBY, H. M. WRIGHT and L. F. WRIGHT \\ John Innes Institute, Colney Lane, Norwich NR4 7UH
}

In Streptomyces coelicolor A3(2), genetic studies have identified a plasmid, SCP1, which is responsible for most of the exchange of chromosomal genes in conjugations between marked strains. $\mathrm{SCPl}^{+}, \mathrm{SCPl}^{-}$and SCPI-prime strains have many features in common with $\mathrm{F}^{+}$, $\mathrm{F}^{-}$and $\mathrm{F}$-prime strains respectively of $E$. coli $\mathrm{K} 12$, but there are also some differences. Donor strains, in which SCP1 is integrated into the circular chromosome, are of at least two kinds, both differing in important aspects from Hfr strains of $E$. coli. Recombination at a low frequency occurs in SCP1- $\mathrm{SCPl}^{-}$matings; whether this is plasmid-mediated is still an open question. Conclusive evidence for plasmid DNA representing SCPI is still lacking, but covalently closed circular DNA of $20 \times 10^{8}$ daltons molecular weight is present in $\mathrm{SCPI}^{+}$and SCPI- strain (H. Schrempf, H. Bujard, D. A. Hopwood and W. Goebel, F. Bact., 121, 416, 1975).

SCPl, as well as functioning as a sex-factor, carries genes coding for some or all of the steps in the pathway of synthesis of an unidentified broad-spectrum antibiotic; it also codes for resistance to this antibiotic.

Mutations in plasmid-linked genes resulting in loss of antibiotic synthesis, and mutations rendering the plasmid defective in transfer, have been used to show that plasmid-plasmid recombination occurs readily.

$S$. coelicolor A3(2) produces a second antibiotic, actinorhodin, and some or all of the genes determining synthesis of this compound are chromosomal.

The occurrence, within streptomycetes, of genes determining resistance to streptomyces antibiotics will be discussed in the context of the theory that such resistances may be the source of those currently found on eubacterial plasmids (R. Benveniste and J. Davies, Proc. Nat. Acad. Sci. U.S.A., 70, 2276, 1973).

\section{GENETICS OF INSERTION DNA-SEQUENCES IN E. COLI}

\author{
H. SAEDLER and H. J. REIF \\ Institut für Genetik, University of Cologne, W. Germany
}

The DNA-sequences IS1 and IS2 are 800 and 1400 base pairs long, respectively. They are known to occur in multiple copies in the $E$. coli chromosome. Presumably they are translocated from their standard positions to other parts of the chromosome, frequently inducing mutations. Since these processes are independent of the cellular rec $A$ gene product, translocation of these DNA elements is an example of the so called illegitimate recombination, not requiring extended DNA homology. Usually illegitimate recombination, like for example deletion formation, is a rare event. As a consequence nothing is known about the enzymes involved in this process. Recently, however, we described a system in which the formation of deletions occurs at an unusually high frequency of about $2 \times 10^{-4}$. This high frequency is dependent on the presence of ISI, and is only observed if the cells are grown at low temperatures. Most deletions terminate at one end of ISI and extend either to the right or to the left to various but preferred chromosomal sites. The high frequency of deletions induced by ISl enabled us to isolate two mutants deficient in this process.

Neither mutation is linked to the chromosomal region at which the deletions arise, and they are therefore likely to be mutations leading to altered enzymes. A better understanding of this system might yield some insight into the mechanism of illegitimate recombination. 


\title{
CLONING OF INSERTED FOREIGN DNA FRAGMENTS IN BACTERIA AS A TOOL FOR THE STUDY OF PROKARYOTE AND EUKARYOTE BIOLOGY
}

\author{
STANLEY N. COHEN, FELIPE CABELLO, ANNIE C. Y. CHANG, \\ DENNIS J. KOPECKO, KAY A. PTASHNE, and KENNETH TIMMIS \\ Stanford University, Stanford, California, U.S.A.
}

Recently developed experimental procedures now permit the cloning in bacteria of DNA fragments derived from diverse prokaryotic and eukaryotic sources. The method involves linkage of foreign genes to a plasmid vehicle capable of propagation in $E$. coli, and introduction of the composite DNA molecule into a bacterial host by transformation. The procedure utilises the properties of the EcoRI restriction endonuclease which cleaves DNA at sites having unique palindromic nucleotide sequences, producing self-complementary cohesive DNA termini which can associate by hydrogen bonding with the ends of other endonuclease-generated fragments. The resulting molecules then can be joined covalently by DNA ligase and introduced into bacterial cells by transformation.

These methods have enabled the construction and study of hybrid plasmids that code for two distinct sets of replication functions by ligation of $E_{c o} \mathrm{RI}$ restriction endonuclease-cleaved pSC101 and Col El plasmid replicons. In addition, the replication regions of several $E$. coli plasmids have been cloned utilizing a non-replicating plasmid DNA segment as a probe. Such specifically constructed DNA molecules have been used to study the relationship of plasmid incompatibility and plasmid replication.

Additional studies have elucidated a process involving $r e c A$-independent insertion of an entire plasmid at a unique site of another plasmid, and excision of a precisely defined DNA segment originally present at the point of insertion. The resulting recombinant molecules can undergo inversion of the original DNA sequence orientation, or translocation of the inserted segment to one of several additional sites. The events involve a palindrome approximately 130 nucleotides long which occurs at both ends of the inserted DNA segment. The relationship of such palindromes to restriction endonuclease recognition sites, and to palindromes formed by insertion sequence (IS) regions will be discussed.

\section{ABSTRACTS OF DEMONSTRATIONS}

\section{A SELECTION FROM THE CORRESPONDENCE AND EPHEMERAL PUBLICATIONS OF WILLIAM BATESON}

\author{
A. G. COCK
}

Department of Biology, Medical and Biological Sciences Building, The University, Southampton

The selection concentrates on Bateson's numerous extra-genetical activities and interests, although not to the complete exclusion of genetics.

\section{GIEMSA BANDING OF PLANT CHROMOSOMES}

\author{
G. E. MARKS and CLAUDIA HESS \\ John Innes Institute, Norwich
}

Giemsa staining of plant chromosomes is demonstrated showing considerable inter and intra-specific differences both in the amount and distribution of Giemsa banded regions. The same technique shows bands which are centromeric, pericentromeric, intercalary or telomeric depending upon the species. The physical nature of the Giemsa bands is problematical, likewise their role in the genetic system of the organism is unknown. Work in progress is concerned with these two aspects using the species Nigella damascena and Anemone blanda. 


\title{
GIEMSA C-BANDING AND THE EVOLUTION OF WHEAT
}

\author{
BIKRAM S. GILL and GORDON KIMBER \\ Department of Agronomy, University of Missouri, Columbia
}

The somatic chromosomes of common wheat, Triticum aestivum L. $(2 n=6 x=42)$, and those of two of its diploid progenitors and $T$. speltoides, have been individually identified by a Giemsa staining technique. In wheat, telocentric chromosomes were used to aid the recognition of individual chromosomes, and an ideogram has been constructed depicting the C-band positions. There is no similarity in the C-banding of chromosomes within a homoeologous group, with the possible exception of group 5. Comparisons of the C-banding of the diploid species $T$. monococcum, $T$. speltoides, and $T$. tauschii with that of the A, B, and D genomes, respectively, in hexaploid wheat corroborate that $\mathcal{T}$. speltoides could not be the donor of the $\mathbf{B}$ genome to wheat and that $T$. monococcum and $T$. tauschii are the probable donors of the $\mathrm{A}$ and $\mathrm{D}$ genomes, respectively.

\section{MEIOSIS IN THE GAMETANGIA OF OOMYCETES}

\author{
E. and F. W. SANSOME \\ 6 Roydon Road, Diss, Norfolk
}

\begin{abstract}
Meoisis in Sclerospora and other genera including Phytophthora is illustrated. Multiple associations believed to be due to structural hybridity have been observed in a number of heterothallic species of Phytophthora including $P$. infestans. These multiple associations afford crucial evidence that the divisions constitute meiosis as indicated by the fact that two consecutive divisions occur without any increase in nuclear or chromosome size between the two divisions. In some cases the chromosomes are so distinctive that chromosome morphology can be used as an aid in analysing the process of sexual reproduction.
\end{abstract}

\section{P-DIPHENOL OXIDASE AND SPORE COLOUR IN ASPERGILLUS}

\author{
A. J. CLUTTERBUCK \\ Department of Genetics, University of Glasgow
}

Yellow spored mutants of Aspergillus nidulans are deficient in p-diphenol oxidase (Clutterbuck, 7. Gen. Microbiol., 70, 423-435, 1972). Colonies bearing spore colours such as white, which are epistatic to yellow, can be tested for $p$-diphenol oxidase by overlaying the mature colonies in a petri dish with filter paper dipped in a solution of $\mathcal{N}, \mathcal{N}$-dimethyl-p-phenylenediamine; positive colonies give a purple colour. This procedure is very suitable for simple class experiments which in a single cross demonstrate three point linkage, independent assortment, epistasis and a gene-enzyme correlation.

\section{TRANSPORT OF METHIONINE AND GLUTAMINE IN MUTANTS OF SALMONELLA TYPHIMURIUM}

\author{
P. D. AYLING and P. R. BETTERIDGE \\ Unit of Genetics, Department of Plant Biology, The University, Hull
}

A class of methionine sulphoximine (METX)-resistant mutants in Salmonella typhimurium possesses two mutations, one affecting a high-affinity transport system for methionine (met $P$ ), the other a transport system for glutamine, ( $g \ln P$ ) (Ayling and Bridgeland, f. gen. Microbiol., 73, 127-141, 1972; Betteridge and Ayling, Mol. gen. Genet., 1975, in press). Other mutants, also isolated on minimal agar + METX, are resistant only in the presence of $L$ methionine; they are mutated in $g \ln P$ alone. MetP is linked in P1-mediated transduction to pro-624 (Mojica-a, unpublished results); $g \ln P$ is close to, but not cotransducible with aroE. 
Transport of methionine by a low-affinity system(s) has been examined in metP mutants. It is partially inhibited by leucine. Mutants have been isolated from a metP met $B$ (methioninerequiring) strain which cannot grow on $L$-methionine in the presence of leucine.

Glutamine is transported by high and low-affinity systems $\left(K_{m}=0.2\right.$ and $10 \mu M$ respectively). $G \ln P$ mutants are defective in the high-affinity system. Although these mutants have lost all glutamine uptake at $0.2 \mu \mathrm{M}$, METX inhibits only 55 per cent of uptake in the wild-type. 